\title{
Change Analysis of Land Use and Urban Growth in the Municipalities of Culiacan and Navolato, Sinaloa, Mexico Using Statistical Techniques and GIS
}

\author{
Geovanna Gpe Hinojoza Castro, Wenseslao Plata Rocha \\ Facultad de Ciencias de la Tierra y el Espacio, Universidad Autónoma de Sinaloa, Culiacán, México \\ Email: hinoj008@umn.edu,wenses@uas.edu.mx
}

Received 6 November 2015; accepted 21 December 2015; published 24 December 2015

Copyright ( 2015 by authors and Scientific Research Publishing Inc.

This work is licensed under the Creative Commons Attribution International License (CC BY).

http://creativecommons.org/licenses/by/4.0/

(c) (i) Open Access

\begin{abstract}
Previous analysis of land use and land cover changes help us to understand the range, importance and effects that this dynamic has in the environment and its relation with the human's activities. This work consists in analyzing the land use/cover for the Municipalities of Culiacan and Navolato, Mexico, through statistical techniques and Geographic Information Systems. The methodology is allowed to determine the changes, gains, losses and transitions in the different categories in the period studied. The results show significant changes in the denominate categories, agriculture and forest. However, the greatest change is the increase of the urban areas. The knowledge in the studied area and its dynamics are carried out and this work serves as a reference to study, manage and plan for our territory.
\end{abstract}

Keywords

Land Use, Change Detection, GIS

\section{Introduction}

In the last decades, many scientists have paid more attention to the changes in land use/cover occurred in the whole plane, which are the result of the rapidly growing of urban areas, deforestation process, agriculture dynamic, fire forest, land degradation and others. Understanding the patterns and processes of land-use and landcover has become a fundamental goal in studies that investigate the complex interactions between humans and the environment from local to global scales [1]. The analysis of the land use and cover changes help to explain 
the range, importance and the effects of the dynamics in the environment and their relation with human activities. Mexico, with a continental territory of near two million square kilometers, is one of the five biologically richest countries, however it is considered as mega diverse [2].

According to FAO, the highest rates of deforestation reported on Mexico for the last decades, the country is located in the position 17 worldwide, with losses of $-195.00 \mathrm{ha} / \mathrm{year}$ in forests [3]. The $38 \%$ of this deforestation is concentrated specifically on the Northeast and Northwest [4].

The state of Sinaloa is located in the northwest region, which has had this dynamic from 1976 to 2006; this represents significant a change in the territory, increasing the land for irrigated and temporal agriculture (296,000 hectares and 376,500 hectares respectively). The most representative change occurs to the municipalities in the center of the state, where it is located at Culiacan the capital of the state which adjoins with the municipality of Navolato, both municipalities maintain an intense dynamic due to its proximity, its agricultural potential and the investment in the tourism development related to the sea of Cortes. Currently, the urban agglomeration of $\mathrm{Cu}-$ liacan is the result of the urban dynamics that the city has been promoting for more than six decades, and tends to the articulation of the countryside and the coast, which induces the formation of a metropolitan area in different addresses mainly between Culiacan-Navolato [5].

Based on the above, it was proposed as the main objective of the analysis in the dynamic of the land use and cover in the municipalities of Culiacan and Navolato, Sinaloa, using a technique that allowed us to detect the changes in the land use/cover and the intensity in three levels; per time interval, category and transitions between categories. For this, we applied the methodology developed by Pontius and Aldwaik in 2007, called Intensity Analysis.

\section{Materials and Methods}

\subsection{Study Area}

Sinaloa is the most important agricultural state in Mexico; and because of its locations in a region naturally fertile it counts with the second biggest fishing fleet of the country. Sinaloa state is located in the Northwestern of the Mexican Republic, specifically in the Gulf of California, adjoins with the state of Sonora at north, Chihuahua and Durango at east, to the south with the state of Nayarit and at the west with the Pacific Ocean. Meanwhile, Culiacan has a territorial extension of about $6283.54 \mathrm{~km}^{2}$ approximately the $10.95 \%$ of the surface of the state, and a population estimated at 858,638 citizens according to the 2010 census. On the other hand, Navolato counts with a territorial extension of $2477.20 \mathrm{~km}^{2}$, around the $4.32 \%$ of the total surface in Sinaloa. According with INEGI the total population in Navolato are about 135,603 citizens [6].

Together, Culiacan and Navolato Figure 1, occupy $8760.84 \mathrm{~km}^{2}$ area of the state, representing the $15.27 \%$ of the total surface of Sinaloa. The city of Navolato is located at $24 \mathrm{~km}$ from the city of Culiacan and the two of them present a phenomenon of conurbation, these two townships are in constant dynamism. In the past years have been presented different kind of changes, changes in the occupation and the land use and the excessive increase of the artificial surfaces (urban areas) [7].

\subsection{Data}

To be able to analyze the changes in the land use/cover in both municipalities were used three maps of the state of Sinaloa, each map was cut out to have the specific area that we need to analyze. These maps were obtained through the governmental and educational agencies such as: the National Ecology Institute (INE, by its acronym in Spanish), overall with The National Statistics and Geographic Institute (INEGI, by its acronym in Spanish), and the Geographic Institute of the National Autonomous University of Mexico (UNAM, by its acronym in Spanish).

All three maps Figure 2 have the same characteristics and were obtained from a visual interpretation. Prior to the analysis, was performed a legend homogenization using only 11 categories of land use of the three maps.

\subsection{Methods}

As mentioned before, to do the analysis of the changes was used the methodology developed by Pontius et al., (2004) [8] and Pontius and Aldwaik (2007) [9], called intensity analysis. This method has been used by a several of authors and the methodology has been changed according to the final objective of the project, in this analysis 
we worked with 2 cross-tabulation matrices (1993-2000 and 2000-2011). In these 2 time intervals we analyzed the changes in terms of size and intensity at three levels of analysis, starting from general to the more detailed level, in order to extract three types of information the following methodological flow was used Figure 3.

In the first level it was analyzing the total change in each time intervals, to examine how the size and annual rate of change vary across time intervals, this level is called "interval level". In the second level "category level" its possible examines each category to measure how the size and intensity of both gross losses and gross gains varies from space. Finally, in the third level called "transition level", it was analyze a particular transition to examine how the size and intensity of transitions varies among categories available for that transition. When a category losses or gain, this level of analysis can identify which other categories are intensively avoided versus targeted for transition by comparing the observed intensity of each transition that would exist if the transition was distributed uniform among categories available for that transition [1].

To obtain the annual percentage of change in the landscape for each time interval its use the following equation, which one gives $T-1$ rates, meaning 1 rate per time interval:

$$
S_{t}=\frac{\text { area of change during interval }\left[Y_{t}, Y_{t+1}\right]}{\text { area of study region duration of interval }\left[Y_{t}, Y_{t+1}\right]} \cdot 100 \%
$$

On the other hand, with Equation (2) we obtain the annual uniform rate of change when we distributed the overall change that occurred during all intervals uniformly from the very first time point to every last time point:

$$
U=\frac{\text { area of change during all intervals }}{\text { area of study region duration of all intervals }} \cdot 100 \%
$$

The gains and losses of each category used for this work were obtained from the Equation (3) and Equation (4)

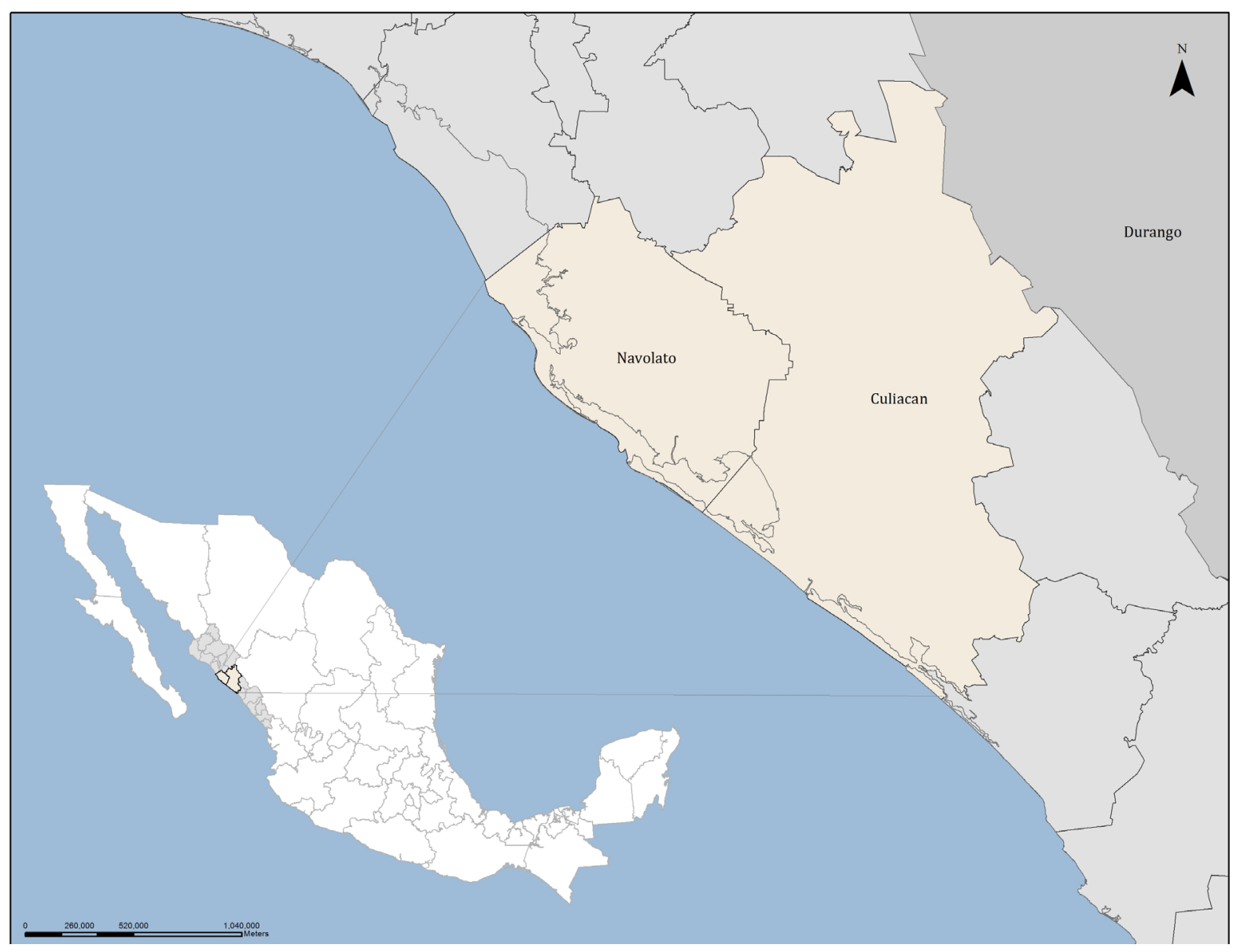

Figure 1. Study area. 


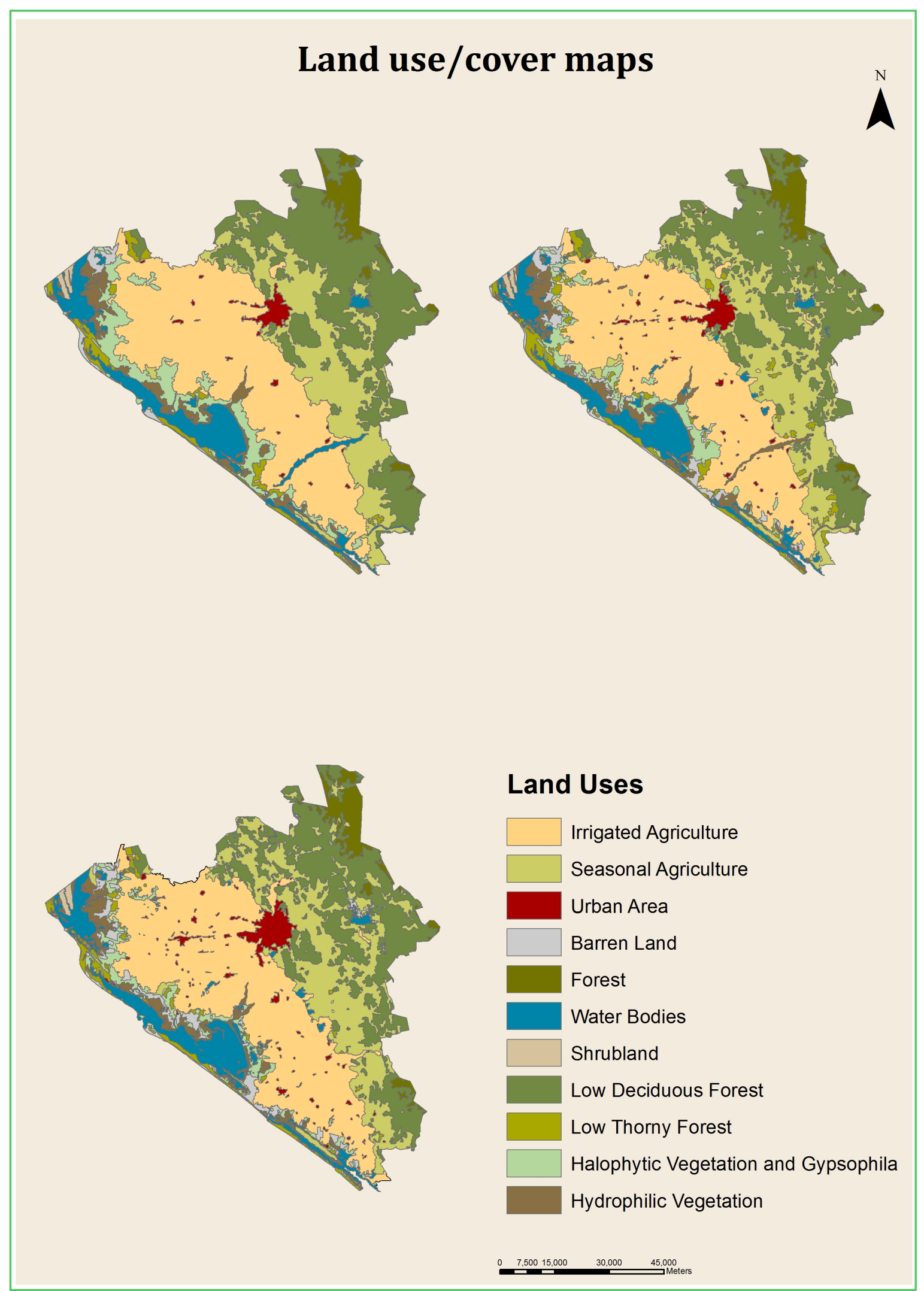

Figure 2. Land use/cover maps (adapted from INEGI maps). 


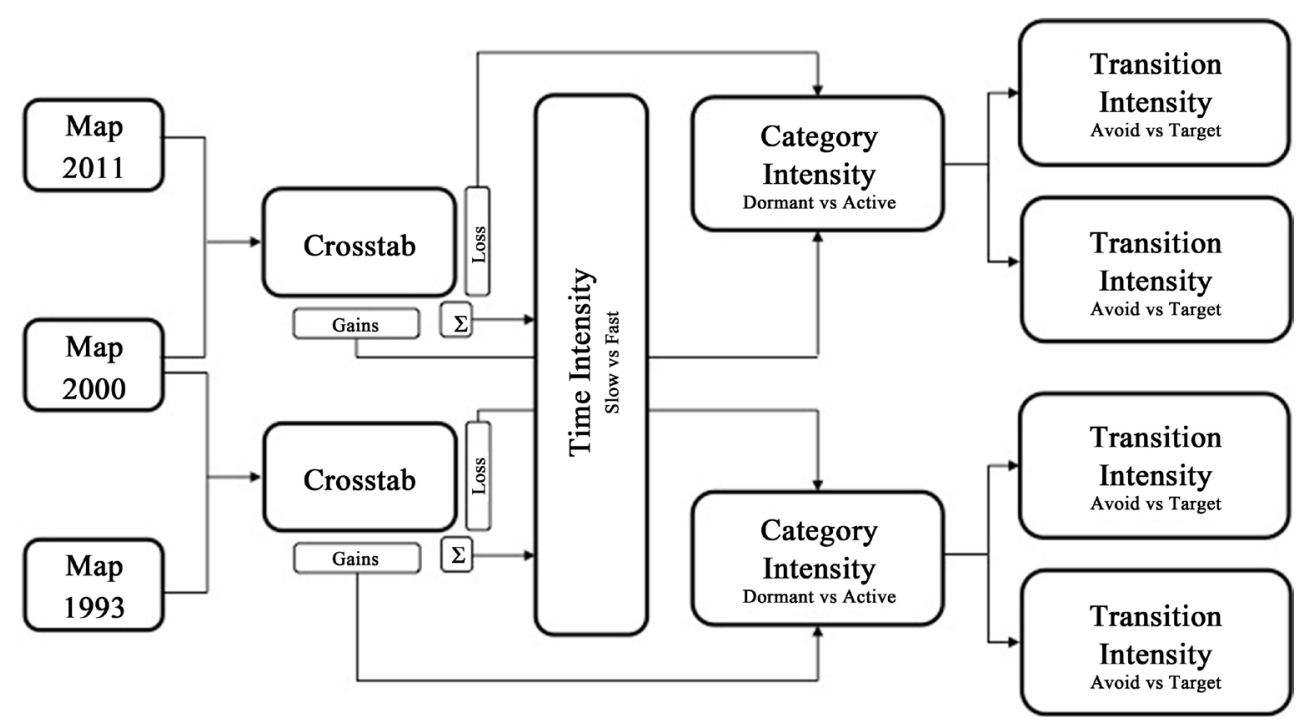

Figure 3. Methodological framework for the change analysis (modified from Aldwaik \& Pontius Jr. 2012).

respectively:

$$
\begin{aligned}
G_{t j} & =\frac{\text { area of gross gain of category } j \text { during }\left[Y_{t}, Y_{t+1}\right] / \text { duration of }\left[Y_{t}, Y_{t+1}\right]}{\text { area of category } j \text { at the time } Y_{t+1}} \cdot 100 \% \\
L_{t i} & =\frac{\text { area of gross loss of category } i \text { during }\left[Y_{t}, Y_{t+1}\right] / \text { duration of }\left[Y_{t}, Y_{t+1}\right]}{\text { area of category } i \text { at time } Y_{t}} \cdot 100 \%
\end{aligned}
$$

At the transition level, it's analyze the intensity of any given transition from one category to another, while accounting for the size of all the individual categories in the landscape. Equation (5) gives the observed intensity of transition to category $n$ from each category $i$, where $i \neq n$. Meanwhile, Equation (6) gives the observed intensity of transition from category $m$ to each category $j$, where $j \neq m$. This equation produces $J-1$ intensities per time interval, meaning one intensity for each non- $m$ category per time interval.

$$
\begin{aligned}
R_{t i n} & =\frac{\text { area of transition from } i \text { to } n \text { during }\left[Y_{t}, Y_{t+1}\right] / \text { duration of }\left[Y_{t}, Y_{t+1}\right]}{\text { area of category } i \text { at time } Y_{t}} \cdot 100 \% \\
Q_{t m j} & =\frac{\text { area of transition from } m \text { to } j \text { during }\left[Y_{t}, Y_{t+1}\right] / \text { duration of }\left[Y_{t}, Y_{t+1}\right]}{\text { area of category } j \text { at the time } Y_{t+1}} \cdot 100 \%
\end{aligned}
$$

Then the Equation (7) produces one uniform intensity for category $n$ that defines the intensity of annual transition to category $\mathrm{n}$ assuming that category $\mathrm{n}$ gains uniformly across the landscape. From the Equation (8), its produces one output for category $m$ that defines the uniform intensity of annual transition from category $m$ to all other categories at the later time point within each time interval:

$$
\begin{gathered}
W_{t n}=\frac{\text { area of gross gain of category } n \text { during }\left[Y_{t}, Y_{t+1}\right] / \text { duration of }\left[Y_{t}, Y_{t+1}\right]}{\text { area that is not category } n \text { at time } Y_{t}} \cdot 100 \% \\
V_{t m}=\frac{\text { area of gross loss of category } m \text { during }\left[Y_{t}, Y_{t+1}\right] / \text { duration of }\left[Y_{t}, Y_{t+1}\right]}{\text { area that is not category } m \text { at time } Y_{t+1}} \cdot 100 \%
\end{gathered}
$$

The analytical method of the quantitative indicators, generating graphs and downloading the program, are widely presented in the Intensity Analysis website (https://sites.google.com/site/intensityanalysis/), in which, Aldwaik and Pontius presented the methodology as follows:

"The unified framework of Intensity Analysis as presented by Aldwaik and Pontius quantifies the behavior of a categorical variable across several time intervals to measure the degree to which changes are non-uniform at 
three levels: interval, category, and transition.

In this website you can learn about the Intensity Analysis framework, know whether error in the maps can explain the observed non-uniform land changes, perform category aggregation thoughtfully, download free computer programs to facilitate the calculations, access publications that have used Intensity Analysis, navigate to useful links, and learn more about the researchers [10]”.

\section{Results and Discussion}

\subsection{Description of Land Use/Cover Changes}

First, it was observed that the land uses with the greater representations in the study area are: irrigated agriculture (35\%), deciduous forest (22\%) and seasonal agriculture (17\%). As well as water bodies, which highlights the importance of the agriculture in the region. Meanwhile, urban surfaces maintain a positive and significant increase in the periods analyzed, even if the increase is only $3 \%$, the impact on other land uses is relevant mainly on agriculture and forest Table 1.

On the other hand, it is possible observe an important dynamic of exchanges and transitions in our region, which shows important losses in low deciduous forest, seasonal agriculture, halophytic vegetation and gypsophila and irrigated agriculture. Likewise, it is noted an important increase in irrigated and seasonal agriculture, predominantly in the second period of time. This is where its possible to discuss spatial transitions in the land uses referred, since in general the surface is maintained, but its geographical location change. In these processes are very important the agriculture activities that occur in the mountain zone of the Culiacan, since it is in this area where the seasonal agriculture is produced, mainly, for growing pasture fed to livestock. It is also important to mention that in this dynamic the growth in the urban areas plays an important role, because the agricultural zones next to the city has been changing Table 1 .

Moreover, it was determined that the total change experienced during the period of 1993 to 2000 was 179,013.06 hectares, less than the one experienced between 2000 and 2011, which reached about 223,216.20 hectares. However, from the intensity analysis, it was found that the first period examined had a dynamic in the land uses greater (1.4\%) Figure 4 than the second (1.15\%) Figure 5, which shows an interesting detail, in this period the change exceeded by more than 40,000 hectares to the first one, the reason can be that the first period of time is shorter and with this analysis we can se observed the intensity with which the changes occurred in general.

\subsection{Intensity Analysis of Land Use/Cover Changes}

Also we could determine for both time periods their intensity to which the gains and losses were given, it is important to mention that these gains, losses and their intensity are annual results. The highest intensities were ob-

Table 1. Land use change indicators in hectares.

\begin{tabular}{cccccccc}
\hline & \multicolumn{3}{c}{ Area in hectares } & \multicolumn{2}{c}{ Gains in hectares } & \multicolumn{2}{c}{ Losses in hectares } \\
\cline { 2 - 8 } Category & 1993 & 2000 & 2011 & $1993-2000$ & $2000-2011$ & $1993-2000$ & $2000-2011$ \\
\hline Irrigated agriculture & $291,615.21$ & $289,359.81$ & $303,498.54$ & 8077.86 & $\mathbf{2 4 , 4 6 2 . 7 2}$ & $10,333.26$ & $10,323.99$ \\
Seasonal agriculture & $148,618.89$ & $154,375.11$ & $161,507.52$ & $\mathbf{2 0 , 9 1 3 . 3 9}$ & $\mathbf{3 3 , 7 2 2 . 6 4}$ & $\mathbf{1 5 , 1 5 7 . 1 7}$ & $\mathbf{2 6 , 5 9 0 . 2 3}$ \\
Barren land & 8764.92 & $19,158.84$ & $26,307.18$ & $12,184.02$ & $11,201.31$ & 1790.10 & 4052.97 \\
Urban area & $10,383.57$ & $15,214.41$ & $23,434.83$ & $\mathbf{4 8 9 8 . 1 6}$ & $\mathbf{8 2 8 8 . 7 3}$ & 67.32 & 68.31 \\
Foret & $27,162.90$ & $28,322.28$ & $28,366.74$ & 1750.05 & 840.06 & 590.67 & 795.60 \\
Water bodies & $65,973.60$ & $63,201.96$ & $65,193.84$ & 4349.88 & 5107.41 & 7121.52 & 3115.53 \\
Shrubland & 3106.89 & 3084.66 & 3279.96 & 345.42 & 626.67 & 367.65 & 431.37 \\
Low decidious forest & $212,490.72$ & $196,026.30$ & $181,857.78$ & 8687.43 & $13,456.89$ & $\mathbf{2 5 , 1 5 1 . 8 5}$ & $\mathbf{2 7 , 6 2 5 . 4 1}$ \\
Low thorny forest & $21,045.69$ & $31,323.96$ & $20,267.28$ & $\mathbf{1 3 , 7 1 0 . 7 8}$ & 2629.35 & 3432.51 & $13,686.03$ \\
Halophytic vegetation & $56,007.99$ & $38,245.32$ & $30,121.02$ & 4090.77 & 6642.63 & $\mathbf{2 1 , 8 5 3 . 4 4}$ & $14,766.93$ \\
and gypsophila & & & & & & \\
Hydrophilic vegetation & $30,906.54$ & $37,764.27$ & $32,242.23$ & $10,252.89$ & 4335.57 & 3395.16 & 9857.61 \\
Total & $876,076.92$ & $876,076.92$ & $876,076.92$ & $89,260.65$ & $111,313.98$ & $89,260.65$ & $111,313.98$ \\
\hline
\end{tabular}


tained during the period of 2000-2011, which shows that seasonal agriculture and barren land (both periods) exceeds the uniform intensity of change for gains and losses. An important fact is the intensity at which the growth occurred in the urban areas for both periods, this reflects the accelerated urbanization in our region, especially in Culiacan, the capital city of the state. Meanwhile, the dynamic of the irrigated agriculture and forests does not exceed the average value of the uniform intensity, due these categories are the ones that predominate in the study area and even though the changes are considerable these are not significant regarding the total surface of these categories and the study area (Figure 4 and Figure 5).

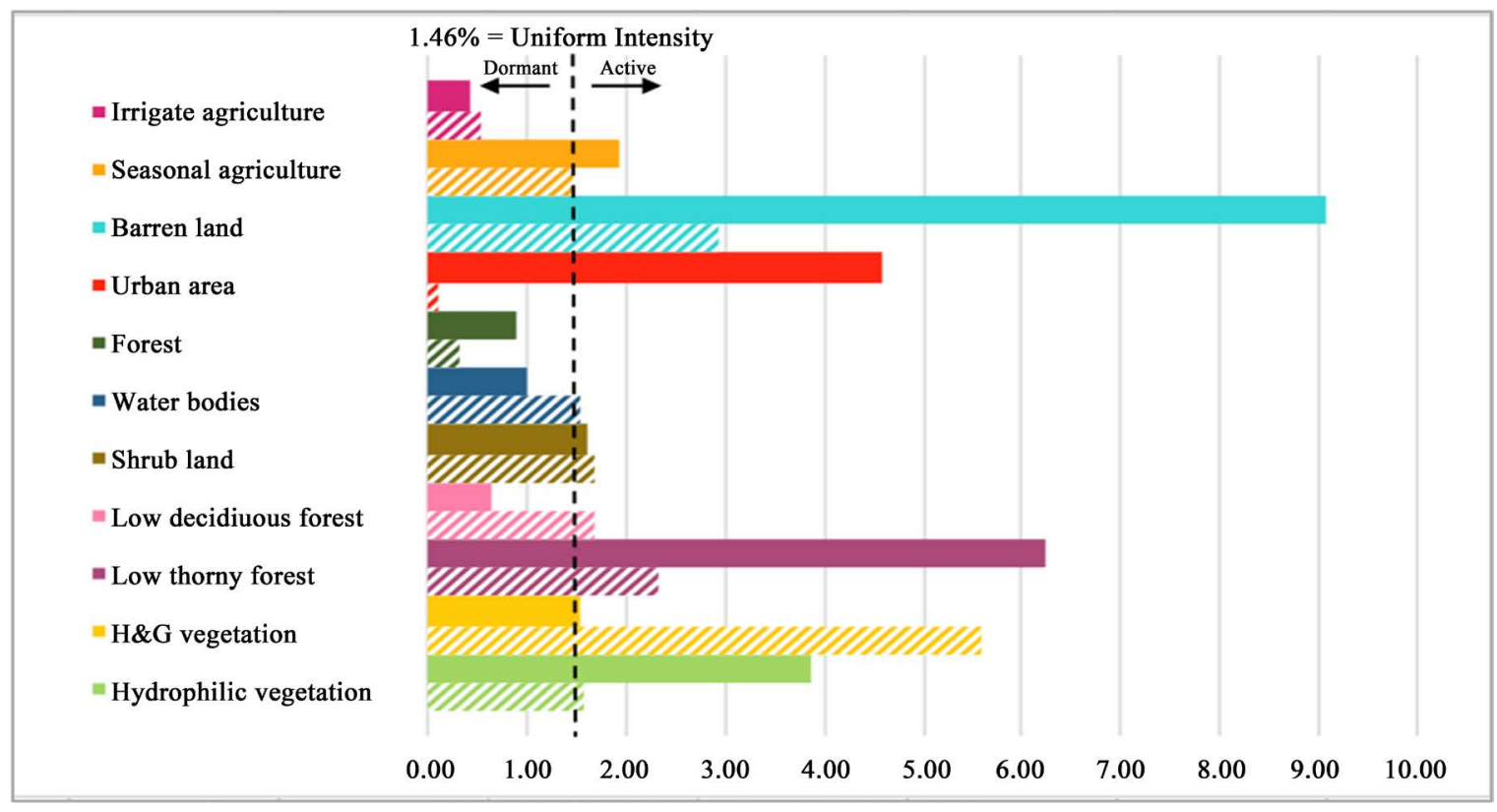

Figure 4. Annual gains and losses intensity for each land use/cover between 1993-2000.

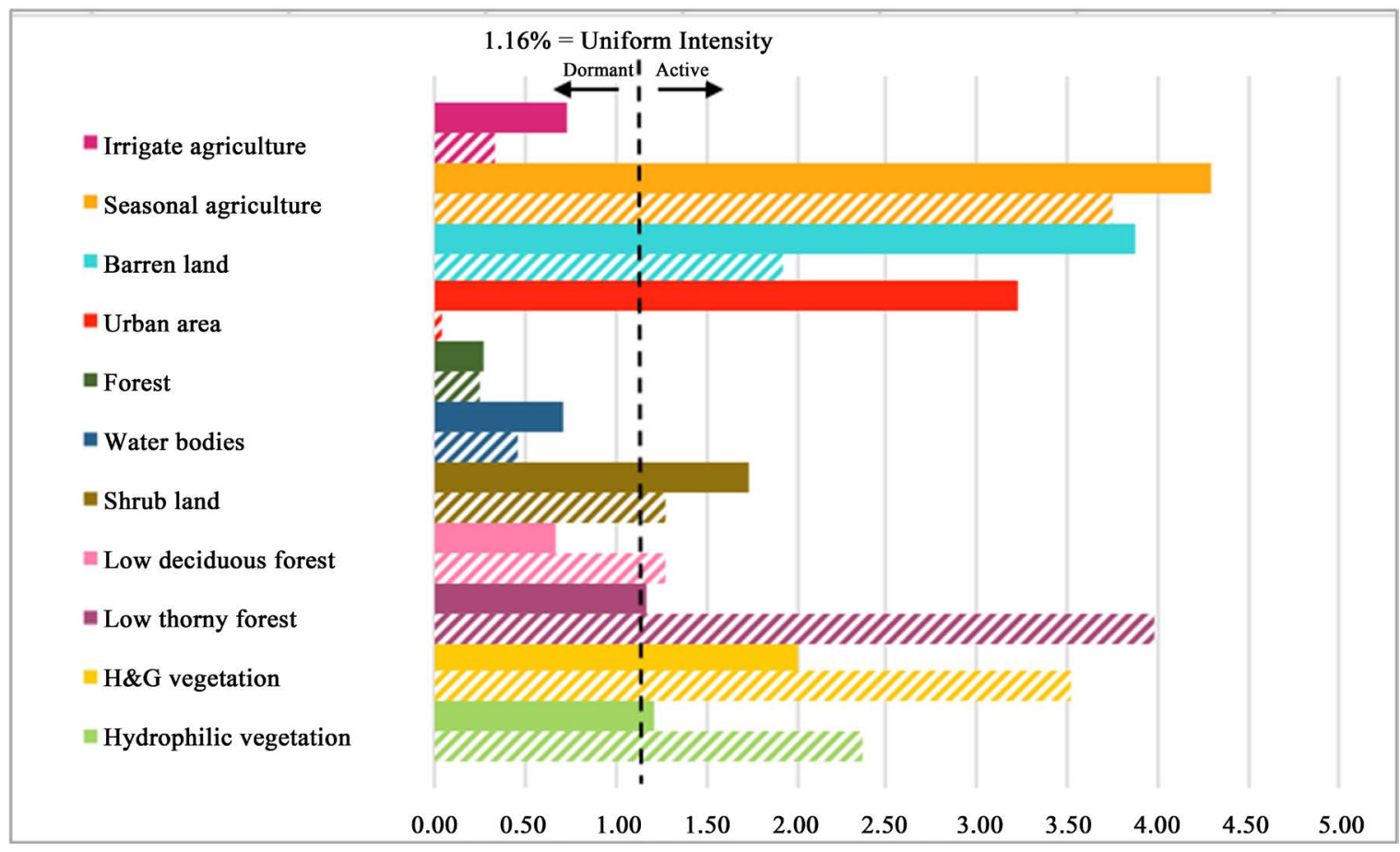

Figure 5. Annual gains and losses intensity for each land use/cover between 2000-2011. 
On the other hand, it was determined the intensity of the annual transitions, from which it was possible to conclude that the loss of irrigated agriculture goes with more intensity to the urban areas in both periods and the gains comes more intense from seasonal agriculture and halophytic vegetation and gypsophila in both periods and from seasonal agriculture in the last period. Meanwhile, seasonal agriculture provides more intensively to urban areas and low deciduous forest in the first period studied, while in the second only to urban areas, barren land and low deciduous forest. As this, is primarily provided by low deciduous forest and low thorny forest. Lastly, it is observe that low deciduous forest have intense transitions to seasonal agriculture and low thorny forest Table 2.

As can be seen, urban areas represent an important part in the dynamic in land use/cover in the area studied, in which it was determined that the main contributions to the increase in this category comes mostly from irrigated agriculture, and the less from seasonal agriculture and low deciduous forest and low thorny forest, having this category the maximum development in the adjacent areas to the city of Culiacan and a less magnitude in the municipality of Navolato and places of both municipalities. Finally, a total of 4898.16 hectares of transitions occurred with an annual rate of 701 hectares between 1993 and 2000, meanwhile for the second period (2000-2011), transitions increase up to 82,888.73 hectares with an annual rate of 753 hectares, reflecting a uniform intensity of 0.08 and 0.09 , practically the same in the both periods (Table 2 and Figure 6).

\subsection{Urban Growth}

From a spatial view, it is possible to observe that the urban growth thrives mainly aggregate in the existing urban areas in 1993, less than in 1993-2000 and with a greater intensity in the period of 2000-2011. Recent studies suggest that the urban dynamic derived in both municipalities are developing a metropolitan area, produced by the economic development of the capital cities and the dynamic in the agricultural and industrial of the mains places in both municipalities Figure 7. If this ends up true, the new metropolitan area will increase its population more than 1,000,000 habitants which represent the 35.92\% of the population in the state of Sinaloa, with $7042 \mathrm{~km}^{2}$ of several urban and rural locations in both municipalities [11].

\section{Discussion and Conclusions}

From the change analysis, it was possible to determine the feasibility applied in the methodology developed by Pontius et al., (2004) [8] and Pontius and Aldwaik (2007) [9], since it allowed to determine not only the gains, losses and transitions but also the intensity in three different levels (period of time, category and transitions), which clarified and gave new information about the dynamic spatial-temporal that was happening in the municipalities of Culiacan and Navolato, Sinaloa. On the other hand, it was possible to certify in quantitative and spatial

Table 2. Annual intensity transitions of the main categories.

\begin{tabular}{|c|c|c|c|c|c|c|c|c|}
\hline \multirow{2}{*}{ From: } & \multicolumn{2}{|c|}{$\begin{array}{c}\text { Transitions to: } \\
\text { Irrigated agriculture }\end{array}$} & \multicolumn{2}{|c|}{$\begin{array}{l}\text { Transitions to: } \\
\text { Seasonal agriculture }\end{array}$} & \multicolumn{2}{|c|}{$\begin{array}{l}\text { Transitions to: } \\
\text { Low deciduous forest }\end{array}$} & \multicolumn{2}{|c|}{$\begin{array}{l}\text { Transitions to: } \\
\text { Urban area }\end{array}$} \\
\hline & $\begin{array}{l}\text { 1st Period } \\
U I=0.20 \%\end{array}$ & $\begin{array}{l}\text { 2nd Period } \\
U I=0.38 \%\end{array}$ & $\begin{array}{l}\text { 1st Period } \\
U I=0.41 \%\end{array}$ & $\begin{array}{l}\text { 2nd Period } \\
U I=0.38 \%\end{array}$ & $\begin{array}{l}\text { 1st Period } \\
U I=0.19 \%\end{array}$ & $\begin{array}{l}\text { 2nd Period } \\
U I=0.18 \%\end{array}$ & $\begin{array}{l}\text { 1st Period } \\
U I=0.08 \%\end{array}$ & $\begin{array}{l}\text { 2nd Period } \\
U I=0.09 \%\end{array}$ \\
\hline Irrigated agriculture & --- & -- & 73 & 65 & 1 & 20 & 3582.45 & 5195.16 \\
\hline Seasonal agriculture & 233 & 1133 & --- & --- & 1092 & 857 & 921.51 & 2128.41 \\
\hline Barren land & 0 & 24 & 0 & 83 & 0 & 0 & 0.00 & 0.00 \\
\hline Urban area & 11 & 5 & 2 & 1 & 0 & 0 & --- & --- \\
\hline Foret & 0 & 0 & 0 & 36 & 84 & 36 & 0.00 & 0.00 \\
\hline Water bodies & 153 & 4 & 83 & 3 & 2 & 5 & 45.63 & 27.09 \\
\hline Shrubland & 0 & 0 & 0 & 0 & 0 & 0 & 0.00 & 0.00 \\
\hline Low decidious forest & 1 & 40 & 2595 & 2284 & --- & --- & 230.58 & 569.52 \\
\hline Low thorny forest & 180 & 255 & 105 & 352 & 62 & 304 & 44.10 & 273.78 \\
\hline $\begin{array}{l}\text { Halophytic vegetation } \\
\text { and gypsophila }\end{array}$ & 576 & 400 & 104 & 145 & 0 & 0 & 73.89 & 72.36 \\
\hline Hydrophilic vegetation & 2 & 363 & 26 & 95 & 0 & 1 & 0.00 & 22.41 \\
\hline Total & 1158 & 2224 & 2988 & 3066 & 1241 & 1223 & 4898.16 & 8288.73 \\
\hline
\end{tabular}




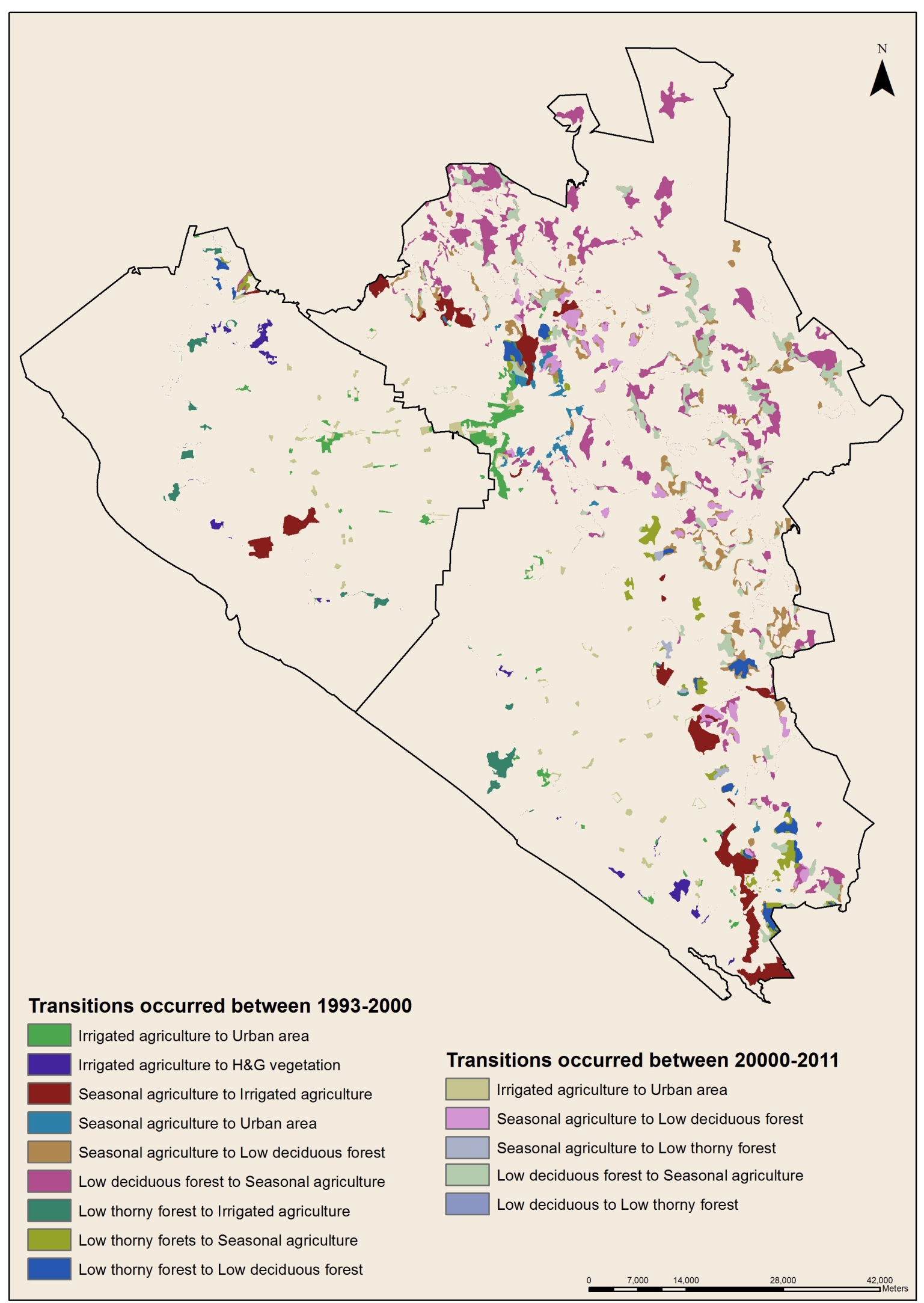

Figure 6. Main transitions occurred in both periods of agriculture and forests. 


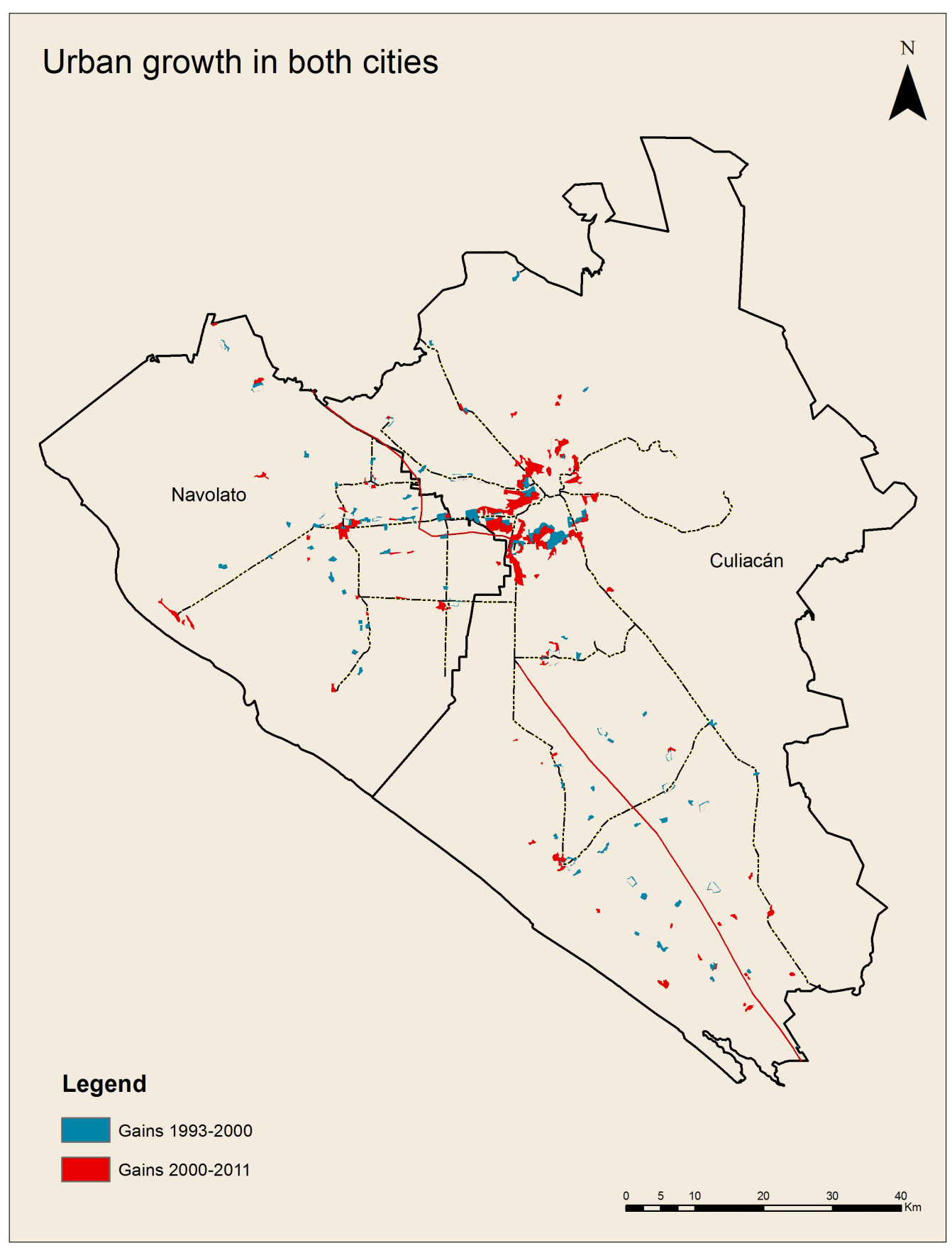

Figure 7. Gains of the urban areas in both periods of time.

way that our study area was in the majority agricultural, but also, the disordered processes under which our territory was subject and which caused damages to the environment and biodiversity. Likewise, it is important to mention the urban dynamics during the last two decades, causing the desertion in the agriculture and the losses in low deciduous forest close to the urban areas that are consolidated for subsequent reclassification to urbanized areas, without counting with good policies for the sustainable urban development for a short or medium period of time.

Note, that this process dated back to the 90s when the program "Programa de Cesion de Derechos Agrarios" was the landowners who had the capability to sell their properties to individuals. It is noteworthy that in some cases selling occurs at the level of areas in communal land which are now zones with high economic level. Def- 
initely, the impact of this process causes the sealing of the land, increase in the temperature of the city, loss of biodiversity in the areas of low deciduous forest and hydrophilic vegetation and where today those areas are residential development. Highlighting the importance of producing land use maps with greater accuracy and range, which define not only the coverage but also the uses to which the land is planned. This will give us the opportunity to study in greater depth the dynamics and intensity of urban growth, as well as simulation models proposed for the future metropolitan growth in our region.

\section{Acknowledgements}

This work was carried out in the framework of PROFAPI 2014/160: "Simulation of 3 scenarios (Trend, Crisis and Sustainability) of land use, through multi-criteria evaluation techniques and GIS. Case of study: the State of Sinaloa, Mexico.

\section{References}

[1] Aldwaik S.Z. and Pontius Jr., R.G. (2012) Intensity Analysis to Unify Measurements of Size and Stationary of Land Changes by Interval, Category, and Transition. Landscape and Urban Planning, Issue 106.

[2] Groombridge, B. and Jenkins, M.D. (2000) Global Biodiversity. S.1: United Nations Environment.

[3] FAO (2014) State of the World Forest. Enhancing the Socioeconomic Benefits from Forests.

[4] Pineda, N. (2010) Descripcion, analisis y simulacion de procesos forestales en el Estado de Mexico, mediante Tecnologias de la Informacion Geografica. Tesis Doctoral, Universidad de Alcala de Henares, Madrid.

[5] Roldan Lopez, H. (2006) La urbanizacion metropolotana de Culiacan, Culiacan; Fontamara, Mexico.

[6] INEGI (2010) Instituto Nacional de Estadistica y Geografia. http://www.inegi.org.mx/

[7] Corrales Barraza, G. (2013) Analisis de cambio de uso de suleo para el Estado de Sinaloa, utilizando Sistemas de Informacion Geografica. Culiacan; s.n.

[8] Pontius, R.G., Shusas, E. and McEachern, M. (2004) Detecting Important Categorical Land Changes While Accounting for Persistence. Elsevier, Issue 101.

[9] Pontius, R.G. and Aldwaik, S.Z. (2007) Intensity Analysis. https://sites.google.com/site/intensityanalysis/home

[10] Intensity Analysis Website. https://sites.google.com/site/intensityanalysis/

[11] IMPLAN (2015) Zonas conurbada Culiacan-Navolato. http://www.implancln.gob.mx/www/zona-metropolitana-culiacan-navolato/ 